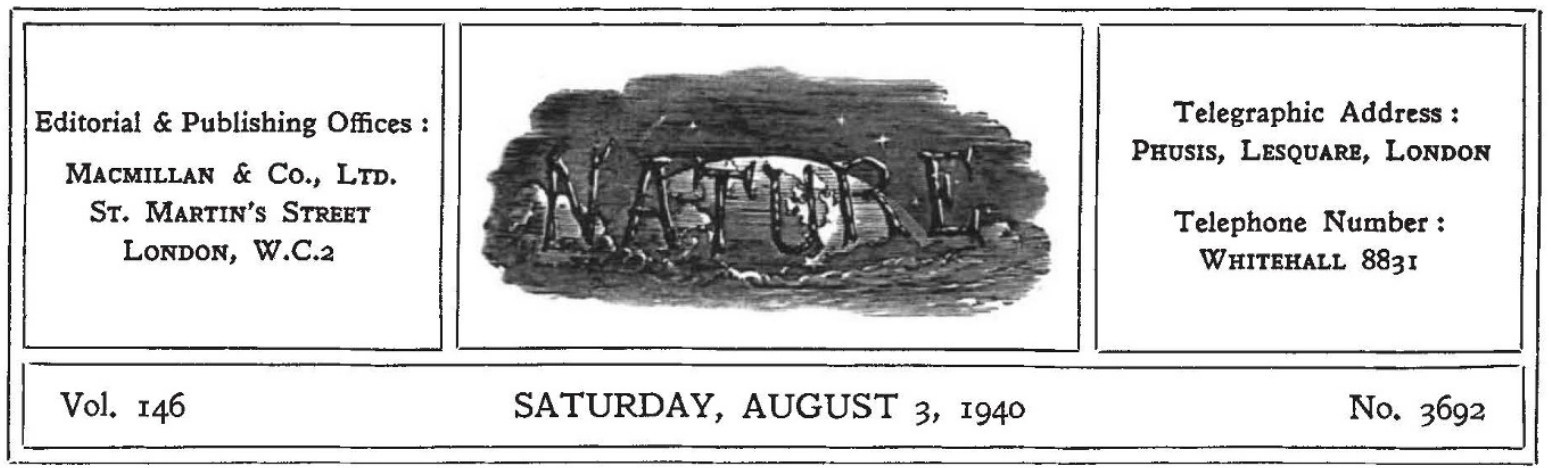

\title{
POTENTIAL AND REAL SCIENTIFIC MAN-POWER
}

$\mathrm{T}$ HE various reports which have already been issued by the Select Committee on National Expenditure have afforded encouraging evidence of a more scientific outlook in the prosecution of our war effort, though there is still room for improvement in attempts to get the maximum utilization of scientific knowledge and resources in the elaboration of policy and in its execution. The eighth of these reports, which comes from the subcommittee on Home Defence Services, deals with matters with which scientific workers are themselves directly concerned.

The first and major of these subjects is the Central Register, which originated as a part of the National Service campaign, the establishment and working of which are critically reviewed. The Register was compiled through the medium of the professional and technical institutions, which circularized their members with an appeal issued on behalf of the Minister of Labour and National Service. In addition, individual applications for enrolment on the technical section of the Register were examined by the committees, and the volunteers were enrolled if found suitably qualified. Applications for enrolment on the administrative and business management sections of the Register were examined by the Department on the basis of standards laid down by the Administration and Management Committee.

Altogether about 50,000 individual applications for enrolment in the Register have been examined since the outbreak of war, of which somewhat less than half have been accepted. On May 20, the live section of the Central Register contained 97,044 names, sorted into 75 main classifications and 735 sub-classifications.

The Central Register is thus an essential part of the organization of the national effort. The report emphasizes, however, that it is not, as is often supposed, an organization for finding jobs for men but for finding men for the jobs. There are still many people of the highest qualifications who appear not to have realized this and have failed to register. The recent order of the Minister of Labour and National Service regarding the compulsory registration of professional engineers, while an indication that registration of engineers is incomplete, is not to be taken as implying greater backwardness on their part than with other scientific and technical workers. It was the first and essential prelude to any considerable use by the Minister of Labour of his wide powers of trans ference and placing of labour of all kinds, whether professional or otherwise. The order is expected to add about 30,000 to the 20,000 names already appearing in the engineering categories of the Register.

The subsequent extension of compulsory registration to chemists, physicists and quantity surveyors shows that the Minister of Labour has lost little time in acting on the sub-committee's recommendation that complete, and therefore compulsory, registration of persons in categories which are, or are likely to become, scarcity categories of the Central Register is essential. No organization of priority is possible without this foundation.

The report's major criticisms are indeed in respect of this question of priority and of the use made of the Central Register. In regard to the first point, there has until recently been no effective machinery for determining labour priority. Obviously the ultimate decision whether to release a man or woman of the Central Register standard from his or her appointment can no longer be left with the employer. Compulsory registration is a 
first step to this end; but the report also points out that the effective placing of scientific or technical staff in industries subject to the Undertakings (Restriction on Engagement) Order, 1940, can be exercised through the Central Register better than through the local office.

Hitherto the main use of the Central Register has been by Government departments and by such bodies as Chatham House and the British Council. This position has led to the erroneous belief that the Central Register is intended to divert highly qualified persons into the Departments rather than into vital war and export industries. The declared object of the Register is to supply additional wartime needs, whether in Government departments or elsewhere, and the sub-committee's recommendations in regard to wider use of the Register are designed to ensure that it plays much more effectively its essential part in the organization of the war effort.

The report recommends accordingly that industrial undertakings under Government control should be immediately and strongly recommended to recruit technical and professional staff from the Central Register. It further recommends that the rule that Government departments should recruit temporary staff of Central Register standards solely through that Register should be strictly enforced, except where it is urgent that the post be filled immediately and where the post to be filled is of a character requiring special qualifications and for which there is a limited field of choice. Even in regard to the latter reservation, it may well be held that use of the Central Register is the more appropriate method, particularly if professional institutions, which in normal times maintain their own appointments bureaux for the benefit of qualified members, maintained sufficiently close contact with the Central Register.

The report undoubtedly implies that more whole-hearted support should be given to the Central Register by individual scientific workers and their professional associations. More specifically, however, it urges that Government departments should assist the Central Register to function more effectively by presenting their demands for technical staff through a technical rather than an establishment officer, to secure the more precise formulation of their requirements. Similarly it is recommended that they should not require full technical qualifications for posts which are primarily administrative, and that they should not be too rigid in their requirements in regard to age.
Expediting the notification of appointments is also urged as facilitating the work of the Register.

The report also comments on the inadequate salaries frequently offered and on the absence of any provision for registering firms of technical consultants, who might be willing to work together as a team. Such teams, accustomed to work together and possessing varied qualifications and experience, would often be likely to be more effective than a technical section of a Government department built up piece-meal. The sub-committee strongly recommends the careful exploration of this source of technical and professional skill at present untapped by Government departments and industries in the war effort.

Obviously a number of these recommendations and suggestions, although addressed primarily to Government departments, merit equally careful consideration by industry if the Central Register is to make its full contribution to our war effort. Moreover, many individual scientific workers are themselves occupying positions of responsibility which enable them to implement such findings, and it may well be hoped that the appearance of this report will lead them to consider very closely the possibilities of thus implementing the co-ordination of our resources of scientific and technical knowledge and skill.

The observations of the report on the neglect of the Central Register of Aliens appear at a time when renewed attention has been directed to the use generally of the services and special knowledge of friendly aliens and refugees in our midst. Both in the Houses of Parliament and in the general Press, the general internment of aliens has received strong criticism even from those who are most fully alive to the necessity of the policy of internment as such.

The question has come into prominence from two points of view ; first in view of its damaging effects on the war effort, and second, from its effect on opinion abroad, alike in providing material for enemy propaganda, in neglect to use those who could be of service to our own cause in that field, and as inconsistent with our traditions and the ideals for which we are fighting. It is, of course, with the first of these alone that the subcommittee's report is concerned.

The Central Register of Aliens has been compiled mainly through the medium of the Society for the Protection of Science and Learning and the refugee agencies dealing with professional classes. It is largely confined to the scarcity 
categories of the main Central Register. The qualifications of these aliens are carefully examined, with the assistance of the chairmen of committees, before they are enrolled. The aliens registered are either friendly aliens or, if enemy aliens, those remaining in Category $\mathrm{C}$ (exempted from all restrictions), where they have been placed by the Home Office tribunals.

The sub-committee was informed that, in general, resort is only had to the Aliens Section of the Central Register to fill those vacancies for which aliens would naturally be expected to be useful, or vacancies in scarcity categories The sub-committee is satisfied that this Register could perform useful service. It contains a wealth of valuable material, including names of international repute. Demands on this section of the Register should not be hindered merely by the failure to devise such safeguards as may be required on grounds of security.

The hope thus expressed by the sub-committee will be echoed by every scientific worker. As pointed out in a recent leading article (NATURE, $145,796 ; 1940)$, any form of preferential treatment of alien scientific workers would carry with it a grave element of risk which could not be justified. While, however, general internment of alien men of science may have been necessary at the time it was carried out as a precautionary measure, neither in science nor in other fields have we such a superabundance of man-power or brains that we can neglect any source of assistance. This was visualized as a possibility in the same article in NATURE. Repeated instances have already been cited in Parliament and in the Press of the actual interruption of war-work through indiscriminate internment of friendly and anti-Nazi aliens, apart altogether from the refusal to accept offers of service from those only too eager to help.

There is little reason to doubt that the actual conditions in the internment camps will speedily be improved, but beyond this a definite aliens' policy is wanted, the absence of which is largely responsible for the worst mistakes or abuses. An aliens' board or commission under a responsible minister is required to supervise the whole problem, look after the welfare of aliens, examine and reexamine their credentials, and use to the full the abilities of those it finds trustworthy. Such an authority might well have prevented the scandals of recent weeks. It should prove the most effective means of implementing the recommendation of the report of the Select Committee and r. aking avail- able for the war effort here and in the overseas Empire the skill, knowledge and good will of many whose services are at present denied to us only by our own policy.

The vigour with which the Minister of Labour and National Service has already acted on other recommendations of the Select Committee, no less than the terms of the appeal addressed to the management of all the 9,000 firms working for the Government by the First Lord of the Admiralty, the Minister of Supply, and the Minister of Aircraft Production, will encourage the hope that this matter will not be overlooked. Sir John Anderson has now announced in the House of Commons on July 23, among other important changes in the treatment of enemy aliens, the formation of a small advisory committee to assist him in considering the question of enlarging the categories of exemption to include particularly those who could render services of special value or make a significant contribution to the war effort. This, with the transfer to the Home Office of the responsibility for managing internment camps, should go far to facilitate the rectification of mis takes, and the new policy has already been warmly welcomed.

Rapid progress should now be made in releasing those who have been wrongfully internedand in making life tolerable for those still confined. At the same time the new policy will still exclude numbers of potential workers, bitterly opposed to Hitler, and wholly on our side, against whom there is no reproach or suspicion. If the most urgent task is that of utilizing the specialist services as fully and quickly as possible, the traditions of Great Britain, and it may well be its ultimate security, will not permit us to rest content with any policy which does not avail itself to the maximum extent of the good will and services at our disposal.

The utilization of the willing services, which we ourselves urgently need, and which are only too anxious to be enrolled, means far more than the mere material accession to our war effort implied. Failure to evolve the necessary safeguards demanded would augur ill for our capacity to embark on the much larger task of establishing a new world order after the war. Integration of such services, skill and knowledge into our effort, on the other hand, will testify to a freedom from hysteria, a capacity for competent organization, and to a loyalty to the ideals and traditions of humanity worthy of the cause for which we contend. 